\title{
LOCAL ARCHITECTURE IN THE AGE OF GLOBALIZATION
}

\section{Dr. Ezzat A. Morghany}

Department of Architecture, Faculty of Engineering, Assiut University, Assiut, Egypt

\section{ezzatmorghany@yahoo.com}

(Received December 23, 2007 Accepted February 21, 2008)

Although the contradicted opinions, the term "GLOBALIZATION" has acquired the attention of economists, sociologists, cultured, and politicians. They are interested in the rapid developments which affect all fields (economic, politics, sociology, ecology ...) and passed the boundaries between the countries, nations and cultures. The media has a clear role in spreading this concept so that the globalization has been considered a historical determinism and with no alternative.

The globalization involves the daily facts and concerning all nations and societies. The built environment is the context of globalization, and the necessity of utilize the epoch technology may contradict with the need to guard the locality of the architecture which make it an art belongs to its culture. So the challenge between the local architecture and global architecture is the main problem of this paper.

The paper aims at studying the concept of local architecture in the age of globalization, and the influence of globalization on the local architectural thinking in contemporary era.

The paper consists of three parts: First one is an exploration of the deferent meanings of the term GLOBALIZATION and its effects on the local concepts, while the second part studies the concept of local Architecture versus the international (or global) architecture, the third part presents a theoretical approach for the local architectural trends in the global era

The paper conclude that: Because of the spreading of globalization concepts, the local architectural trends will go in one of two ways; One of them is: architectural trends will go against the global trends, and it will use the architecture as a defense tool to announce its particular identity through RE-PRODUCTION of local models, and it may use exaggerated details. The other one is: architectural trends will go with the global trends and the architecture will be one of the ways which will be used to announce the belonging of globalization through COPYING formal models from the leading countries of globalization. The second one is expected to be the strong trend in the weak parts of the globalization ring 


\section{العمارة المحلية في عصر العولمة

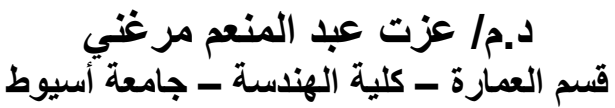

ملخص:

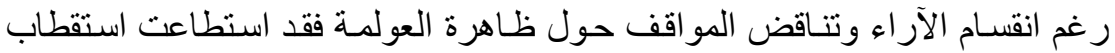

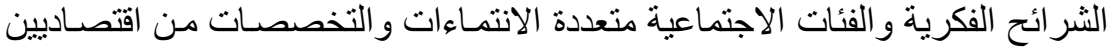

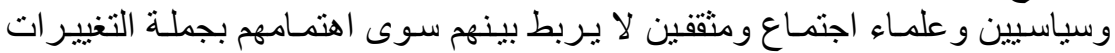

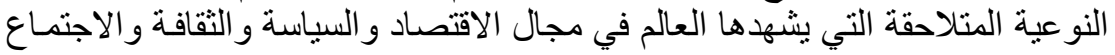

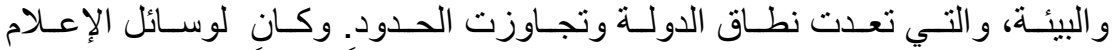

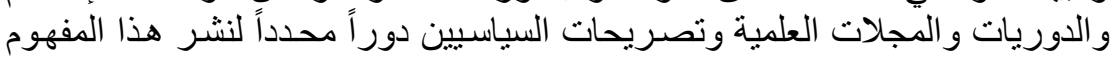

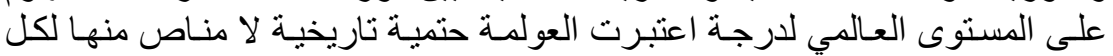
شعوب العالم.

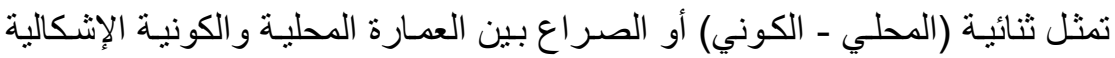

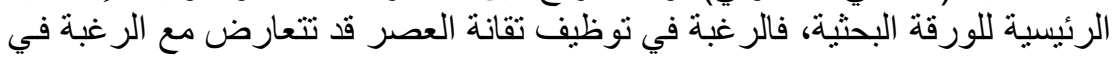

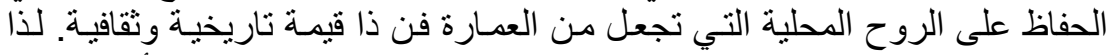

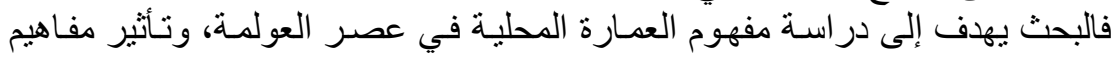

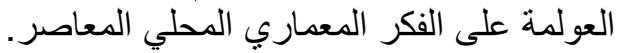

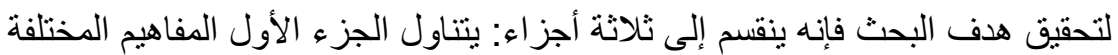

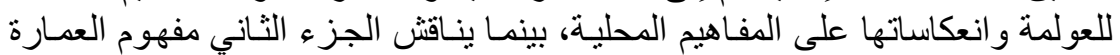

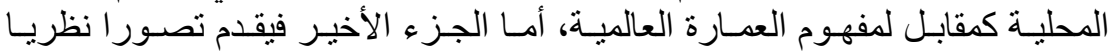

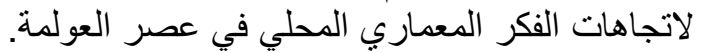

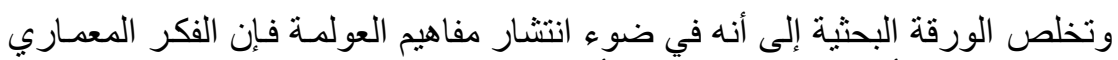

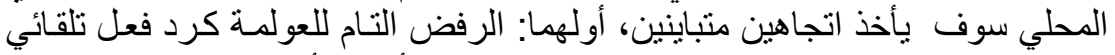

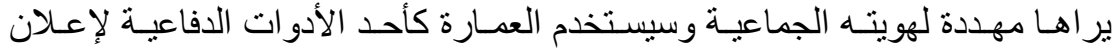

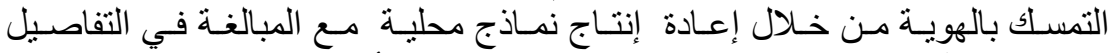

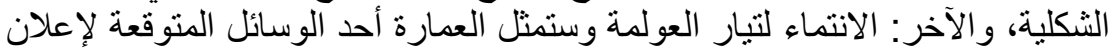

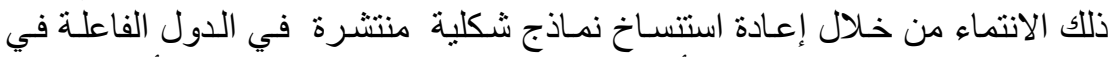

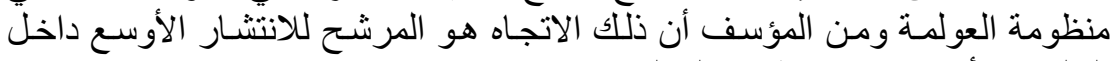
الحلقات الأضعف في منظومة العولة العولمة. كلمات مفتاحية ( العولمة_العمارة المحلية ـالعمارة العالمية- الاتجاهات المحلية)

\section{1/ مدخل تمهيدي (المشكلةـ الهذف - المنهجية)}

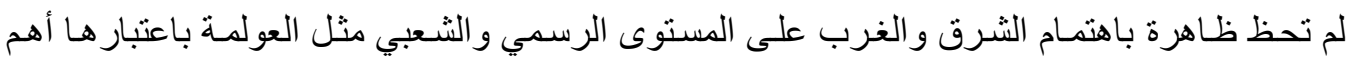

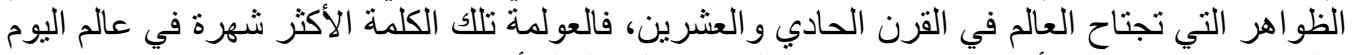

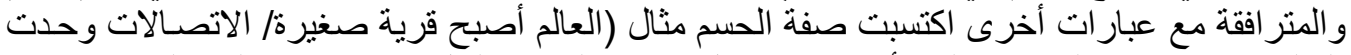

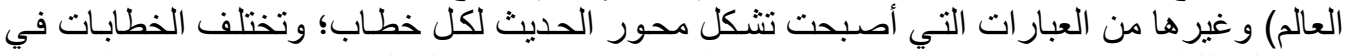

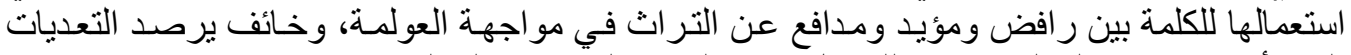

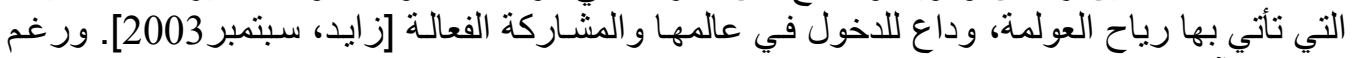

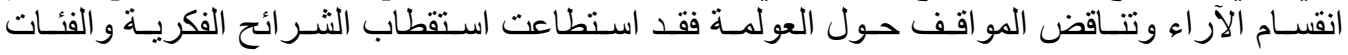




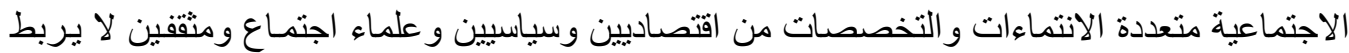

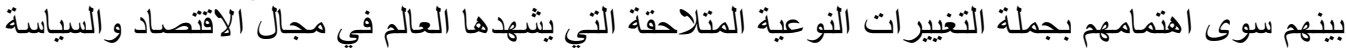

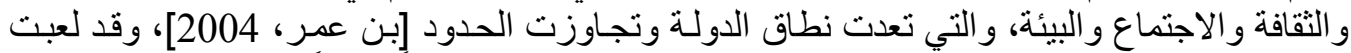

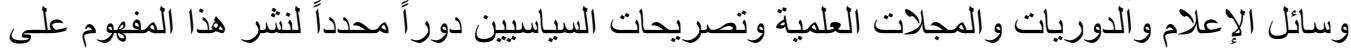

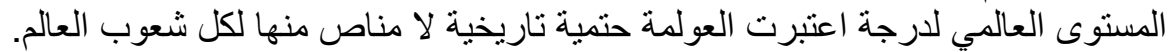

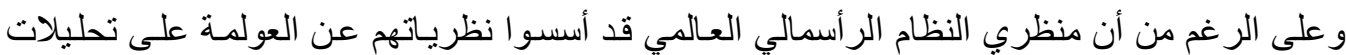

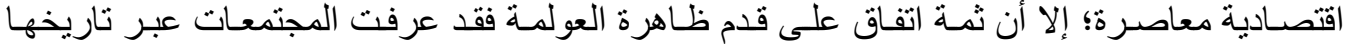

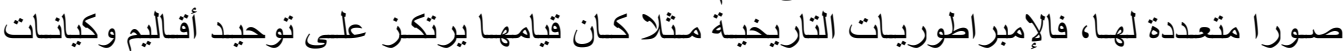

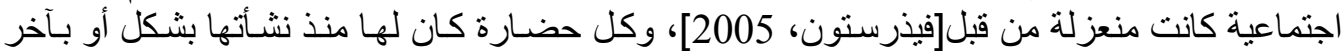

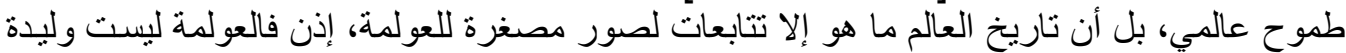

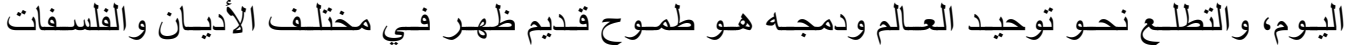

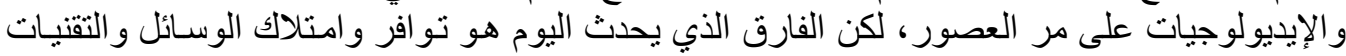

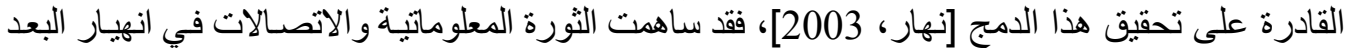

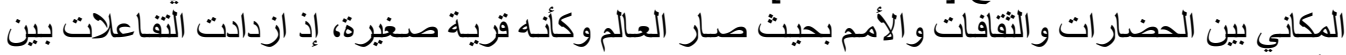

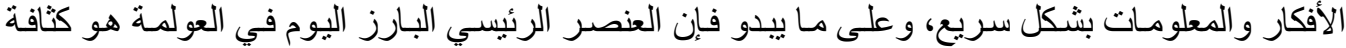

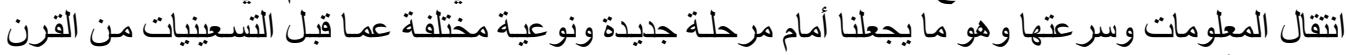

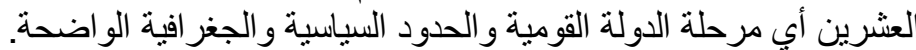

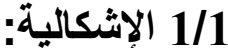

تهدف العولمة ـ من وجهة نظر باحثين كثيرين ـ إلى توحبد العالم على أساس نظام نموذجي أحادي يلغي

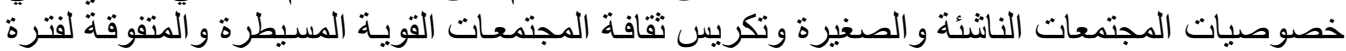

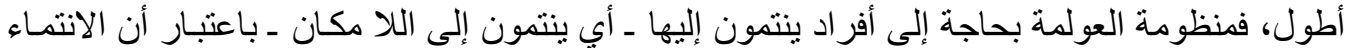

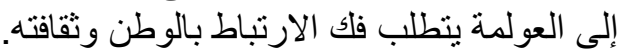

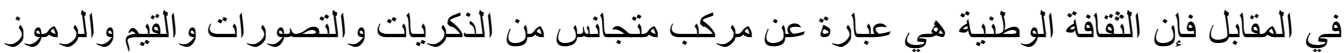

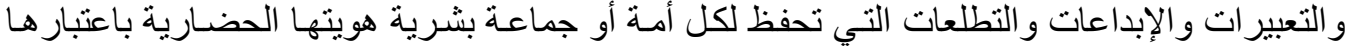

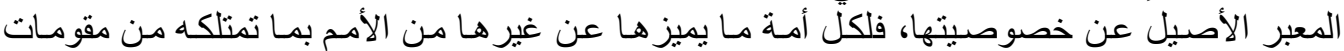

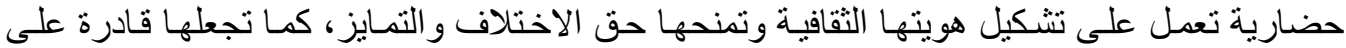

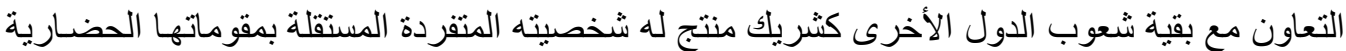

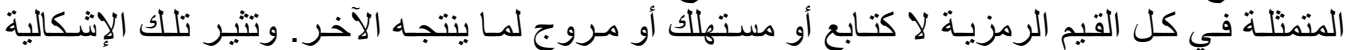

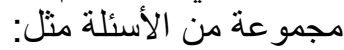

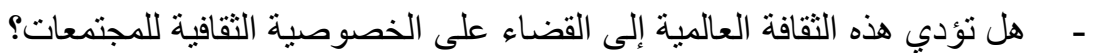

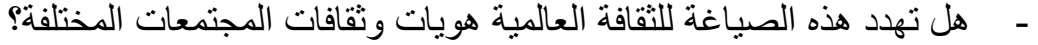

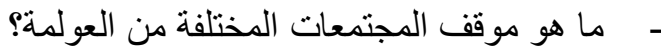

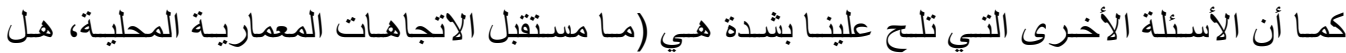

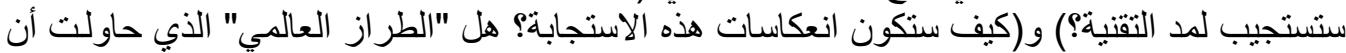

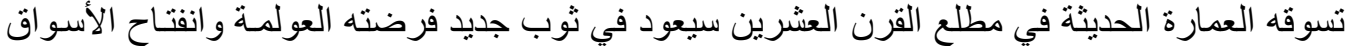

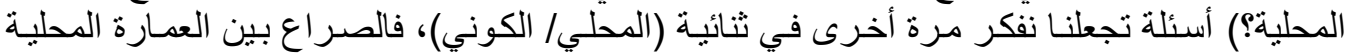

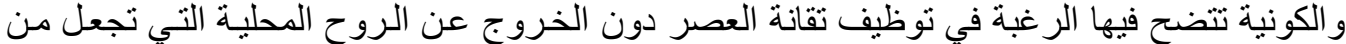
العمارة فن ذا قيمة تاريخية وثقافية.

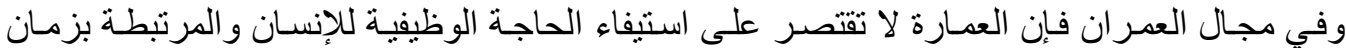

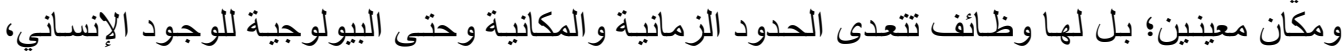




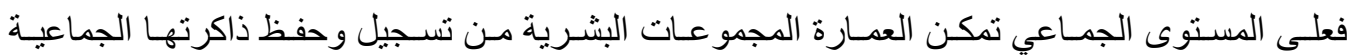

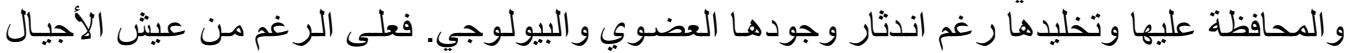

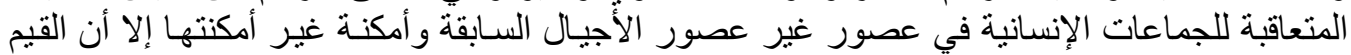

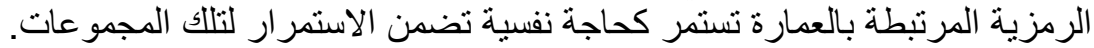

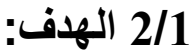

يهدف البحث إلى دراسة العمارة المحلية في عصر العولمة وتأثير مفاهيم العولمة على الفكر المعماري المحلي المعاصر.

3/1

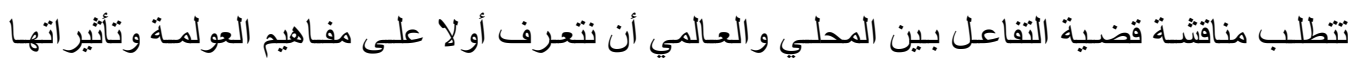
المختلفة، ومن ثم يمكننا مناقثة تأثثير ها على العمارة المحلية، لذا فالبحث في سبيل تحقيق العيق هدفه يتناول

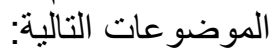

$$
\text { - }
$$

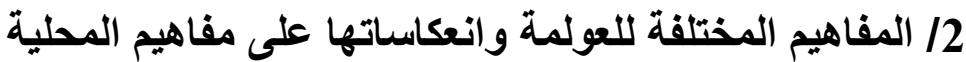

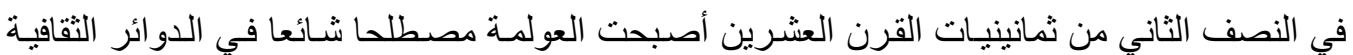

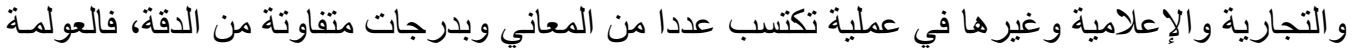

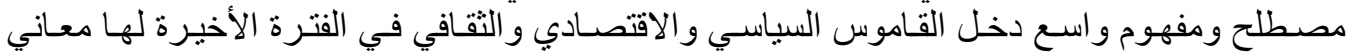

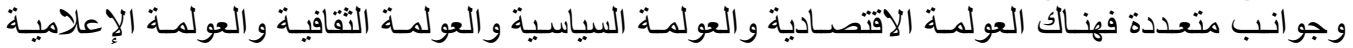

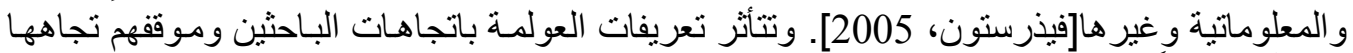

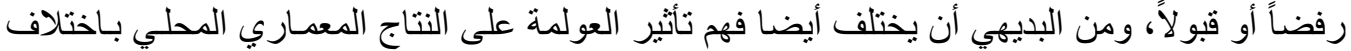

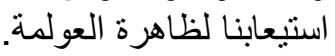

\section{1/2 العولمة.... المفاهيم}

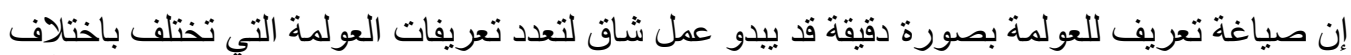

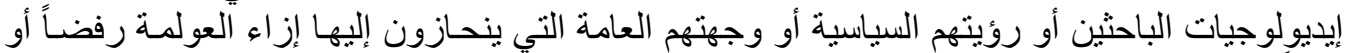

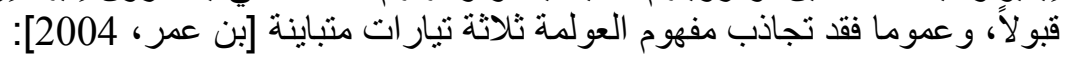

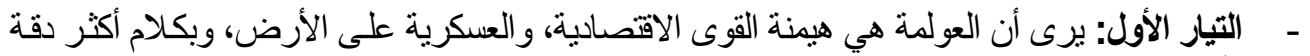
"أمركة" النظام الاقتصادي والسياسي والنقي التقافي والاجتماعي.

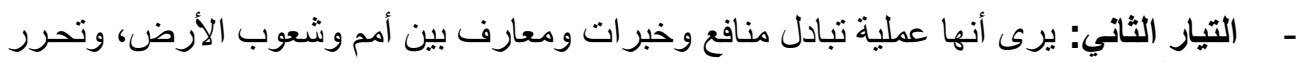
وتكامل اقتصادي.

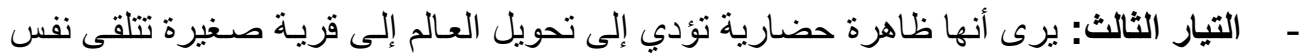

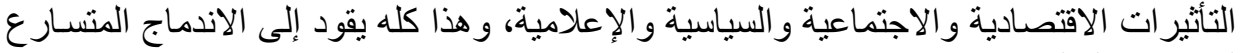

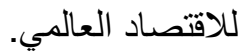

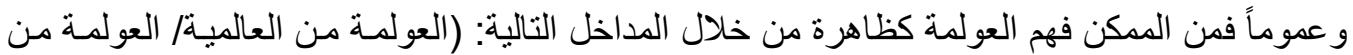

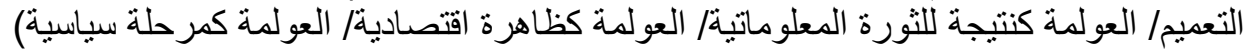

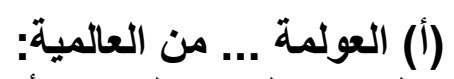

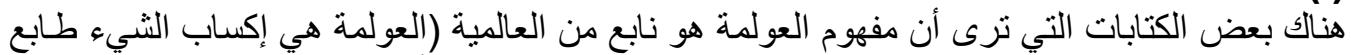

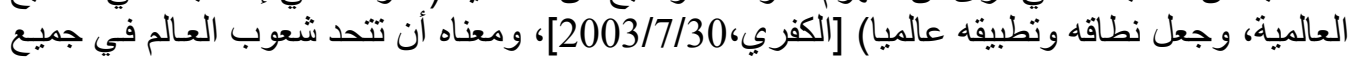




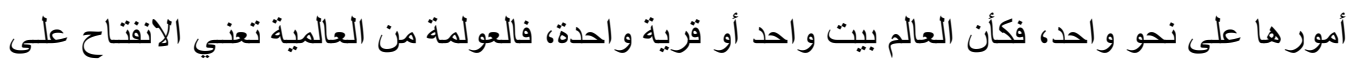

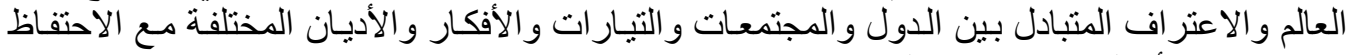

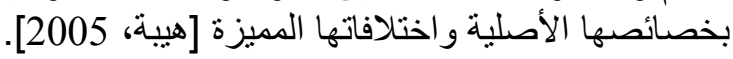

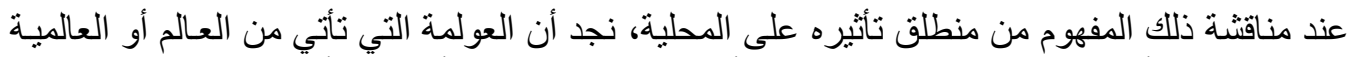

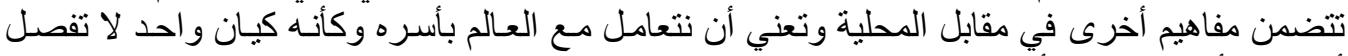

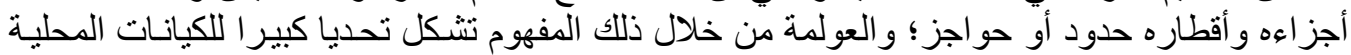

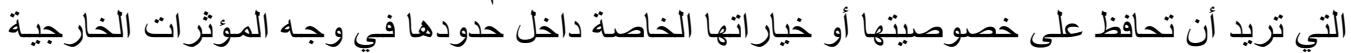

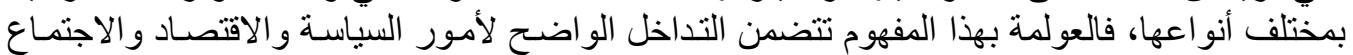

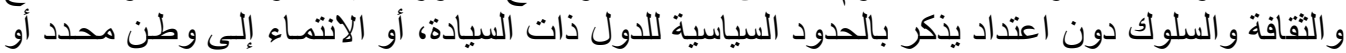
لدولة معينة]|لكفري،2003/7/17].

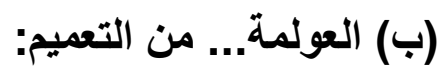

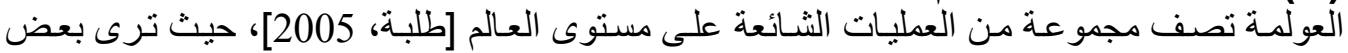

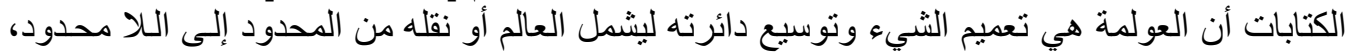

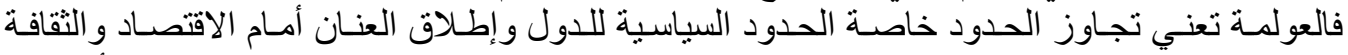

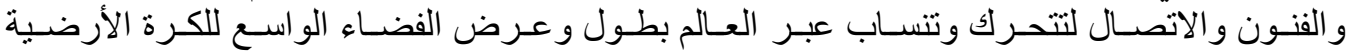
[هيبة، 2005].

ودن خلال هذا المفهوم فإن العولمة تتضمن نقل التقافات الأقوى وتعميميها على الكيانات الأقل تأثيراً وبالتالي قد تمثل تحديا للأفكار المحلية حيث ستصبح النماذج العالمية المرتبطة بالثقافات الأكثر انتشـارا هي النموذج المطروح للتعميم.

\section{(ج) العولمة نتيجة للثورة المعلوماتية:}

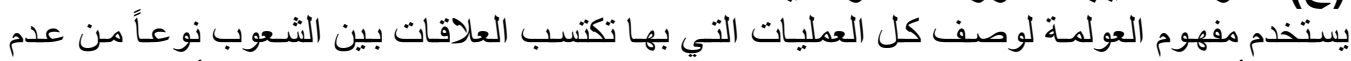

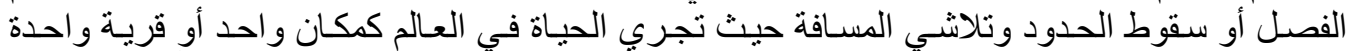

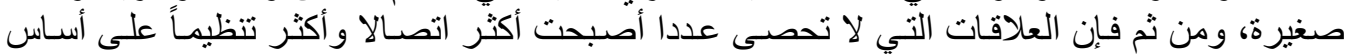

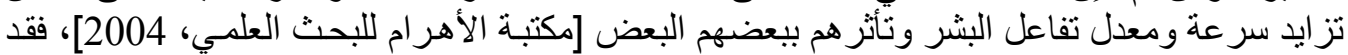

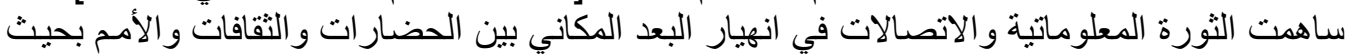

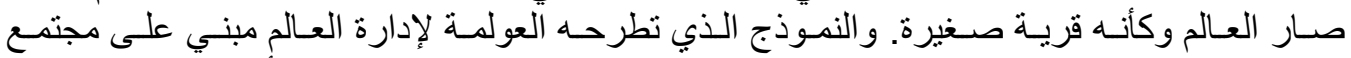

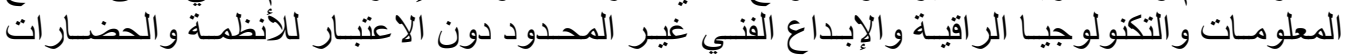

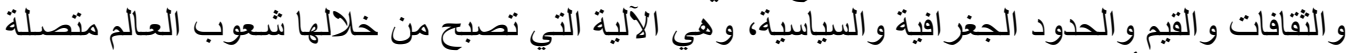
ببعضها في كل أوجه حياتها [طلبة، 2005]

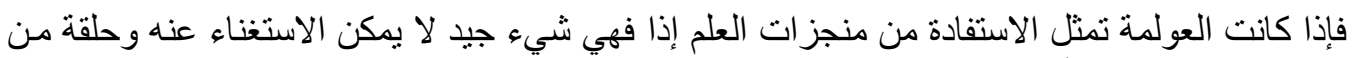

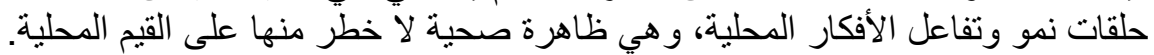

\section{(د) العولمة ظاهرة اقتصادية:}

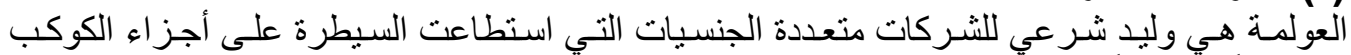

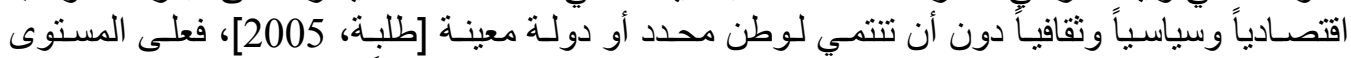

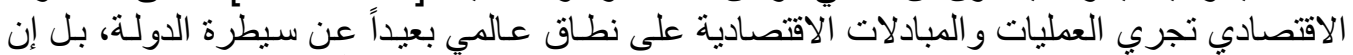

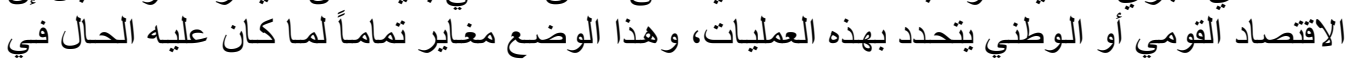

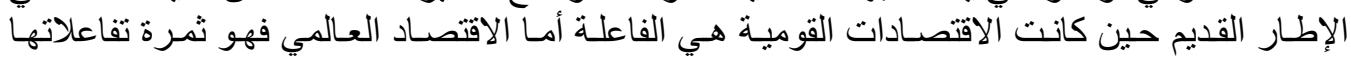


ومن خلال ذلك المنظور فإن العولمة هي طريق باتجاه واحد غير قابل للتغيير، وظاهرة لا سبيل لتجاهل

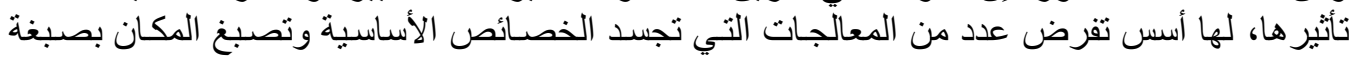

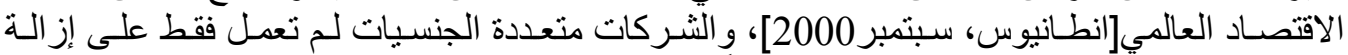
التأثير ات الإقليمية الر اسخة بل جلبت معها أيضاً بعض العنائر العناصر المميزة للمدينة الغربية.

\section{(هـ) العولمة مرحلة سياسية:}

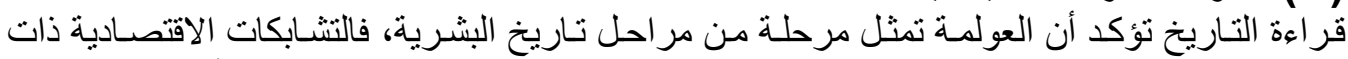

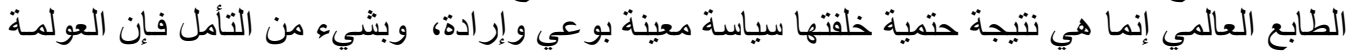

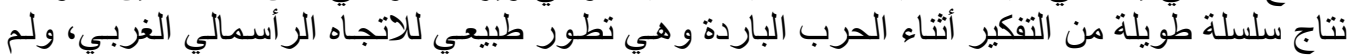

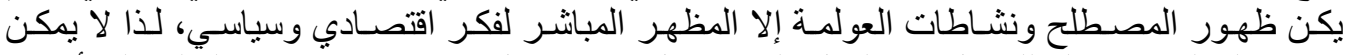

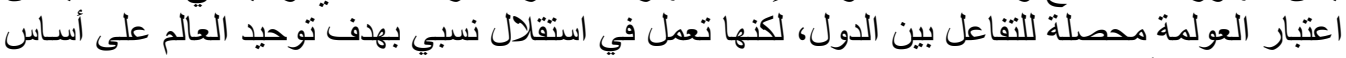

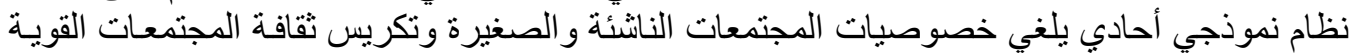

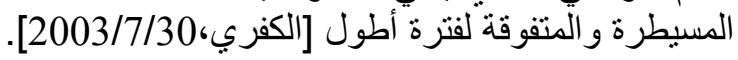

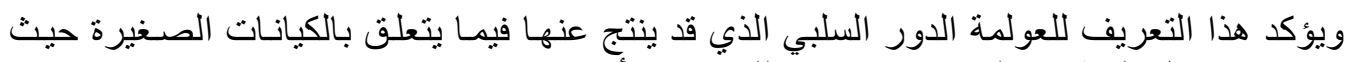

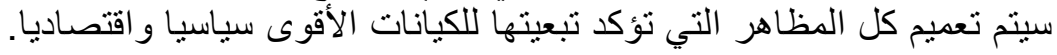

\section{2/2 2 العولمة.... التأثير}

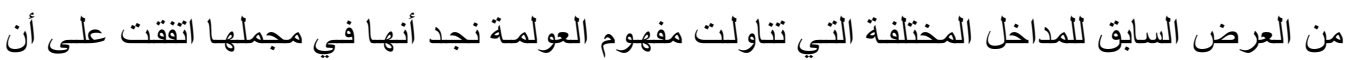

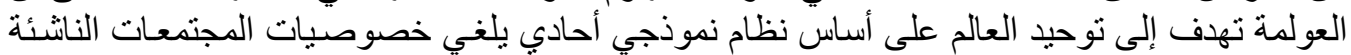

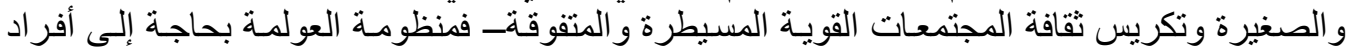

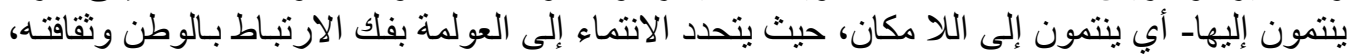

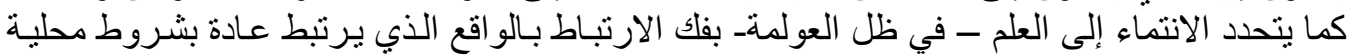

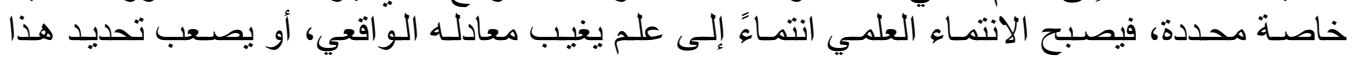

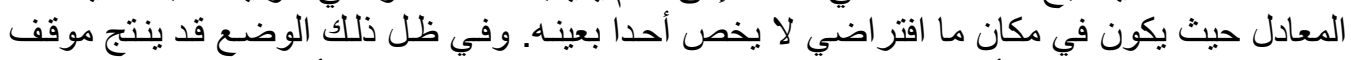

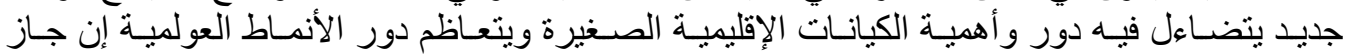

التعبير.

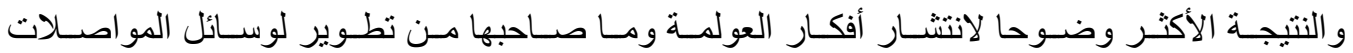

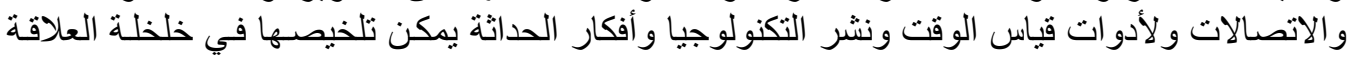

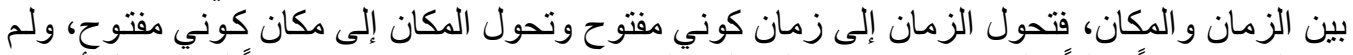

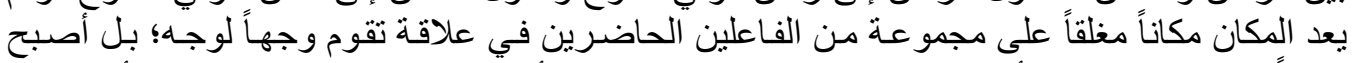

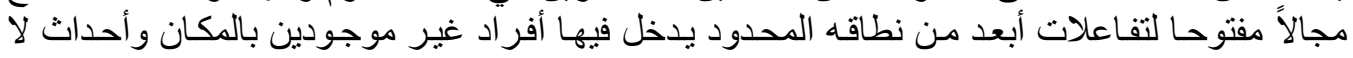

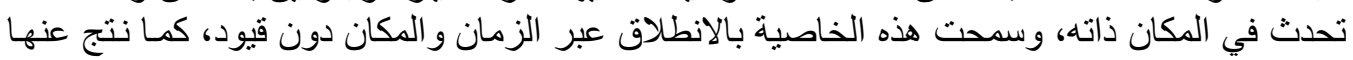

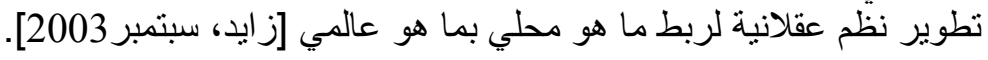

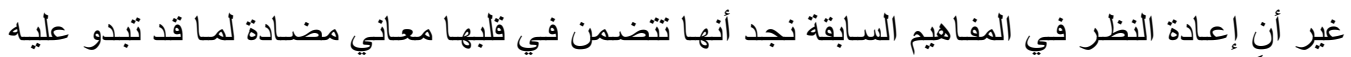

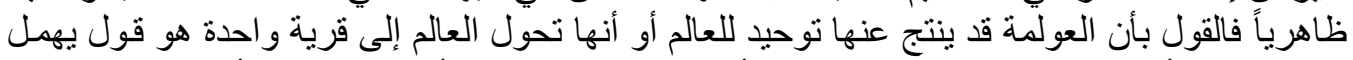

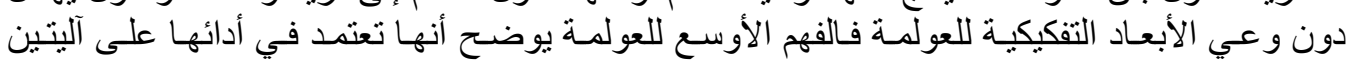

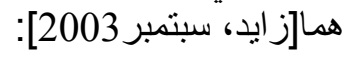

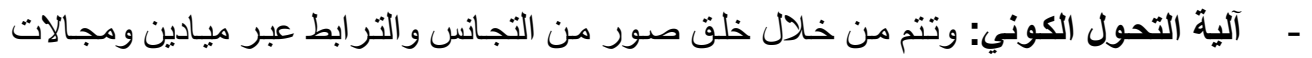

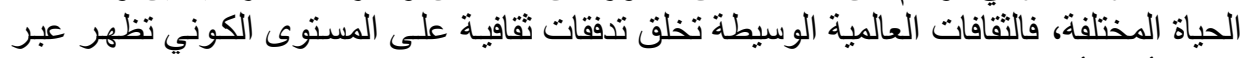

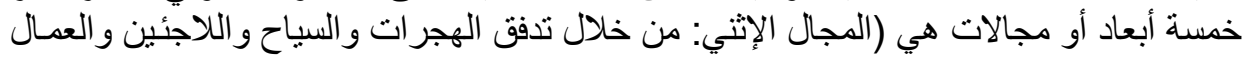

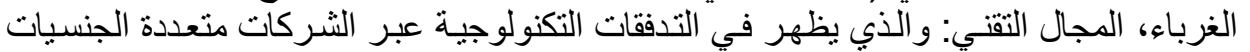

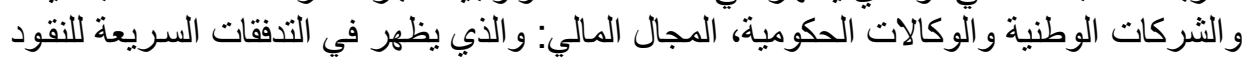




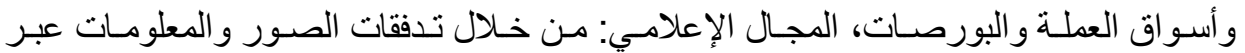

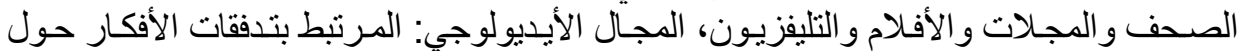

الحرية و الديمقر اطية و التنوير)

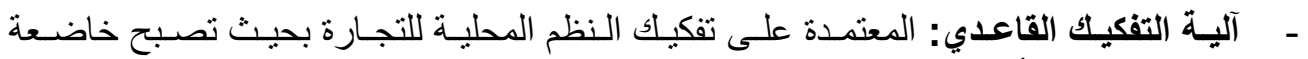

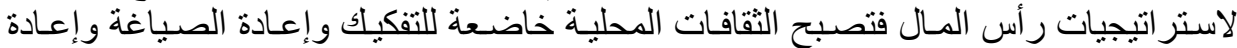

التكيف مع الوضئ التجع الجديد.

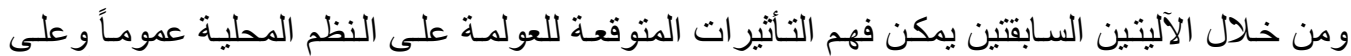

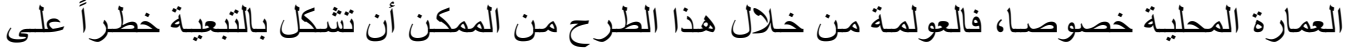

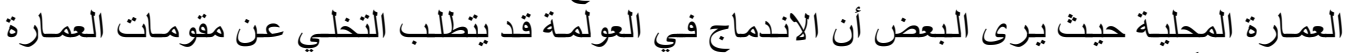
المحلية بحثناً عن الاندماج في العالمية.

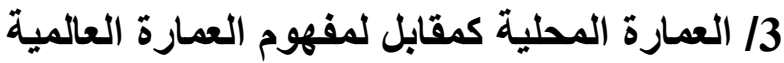

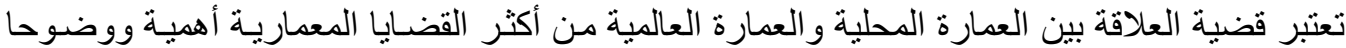

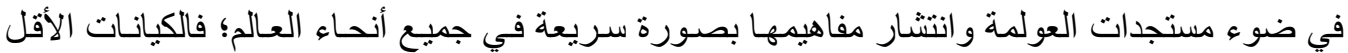

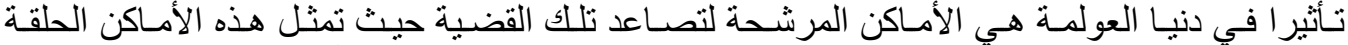
الأضعف نظريا في عالم العولمة، فهي المتلقي للتقافات الأقوى و الأكثر انتشار أ.

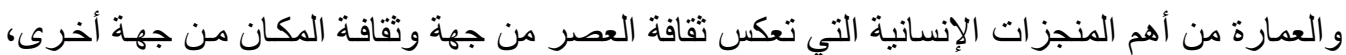

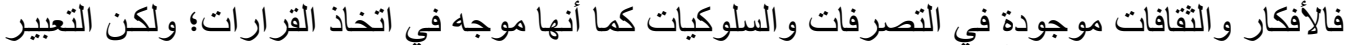

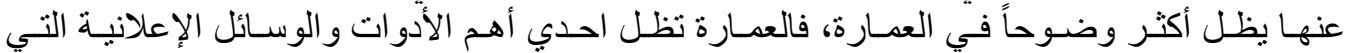
تستخدمها الشعوب للتعبير عن تطلعاتها وعن ما تتبناه من قيم ثقافية سو اء لتأكيد الخصوصية أو الإعلان التان

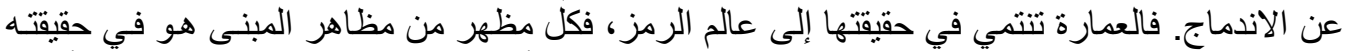

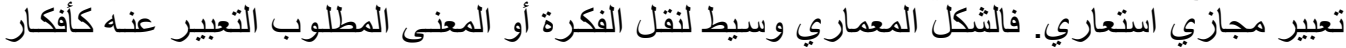

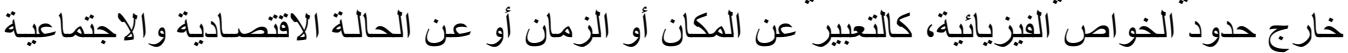

.[Eisnman, 1988]

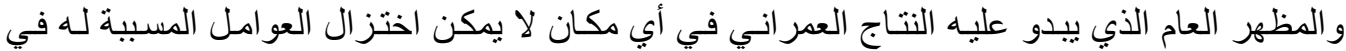

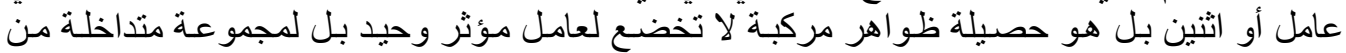

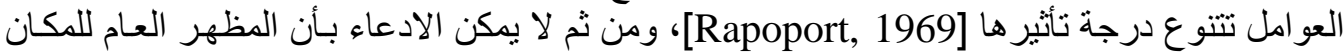

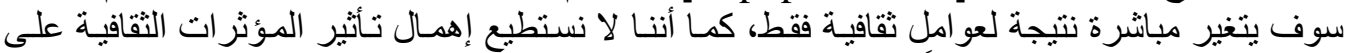

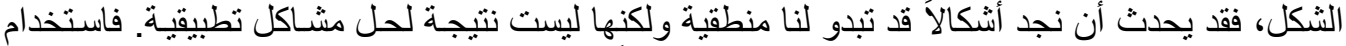

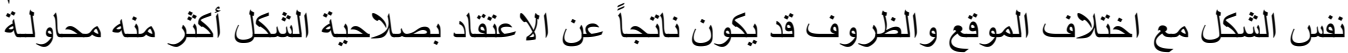

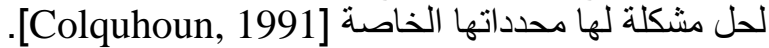
وفي ضو اء الفهم السابق للعمارة كو عاء معبر عن التغيرات الثقافية التي تمر بها الثها الثعوب، بمكن القول بأنتا في حاجة للاتفاق على أهم ملاح العمارة المحلية في مقابل العمارة العالمية.

\section{1/3 العمارة المحلية}

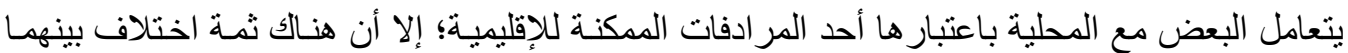

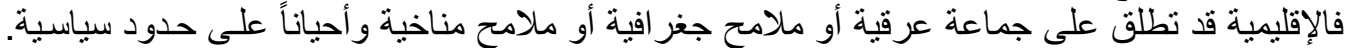

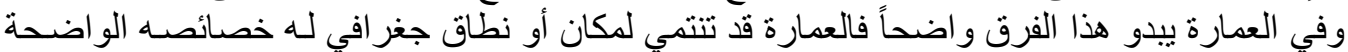

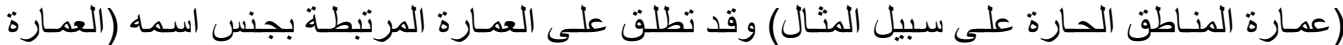

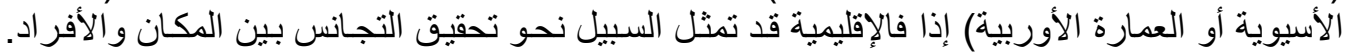
بينما المحلية تحمل في جنباتها ثلاثة خصائص الألئ منكاملة هي: 


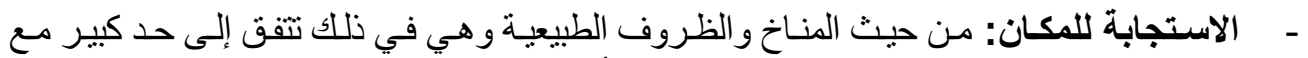

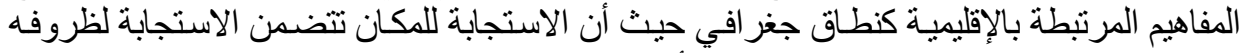

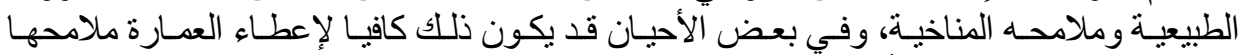
الخاصة وشخصيتها المميزة. - الاستجابة الثقافية: وتعني التعبير عن المقومات الثقافية و الهوية الحضارية للأفر اد، وفي مجـال

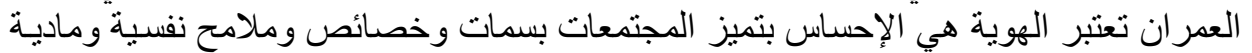

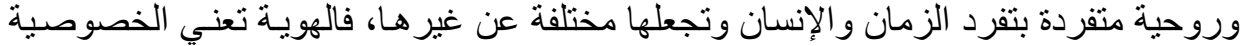

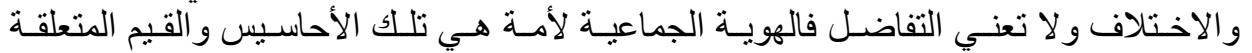

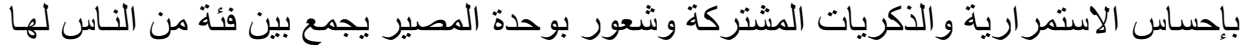

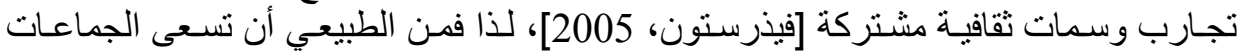

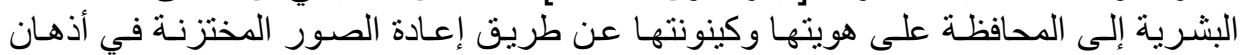

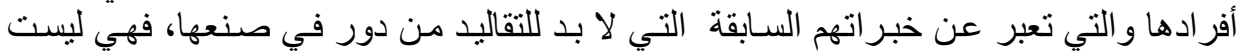

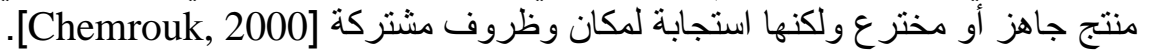

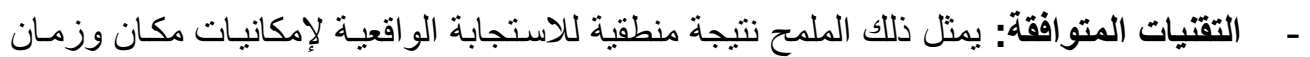

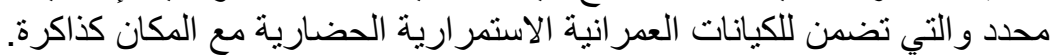

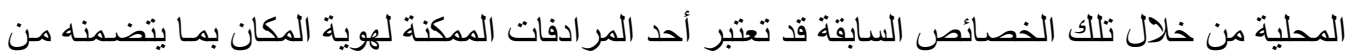
ملامح مادية ومعنوية، فالعمارة المحلية عبارة عن بناء متكامل الصور المتر ابطة و الانطباعـات الذهنية عن المكان و الزمان. ماند.

\section{2/3 العمارة العالمية}

يمكن القول بأن مفهوم العمارة العالمية ارتبط في بداياته بالطراز الدولي، والذي مثل أحد أهم الاتجاهات

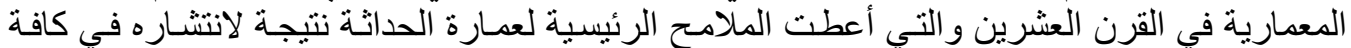

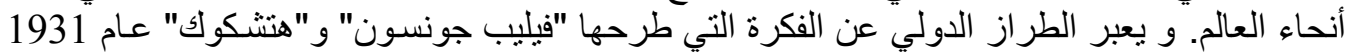

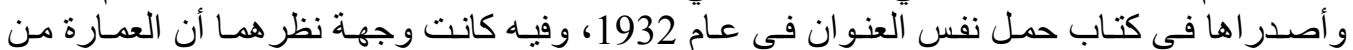

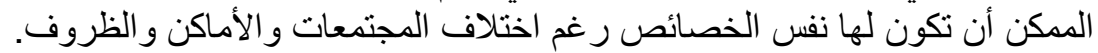

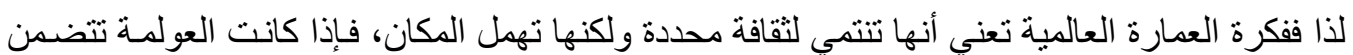

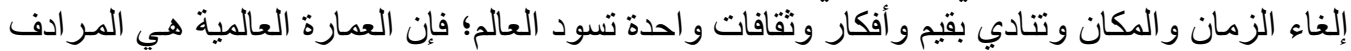

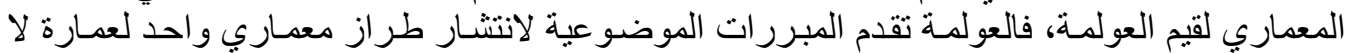

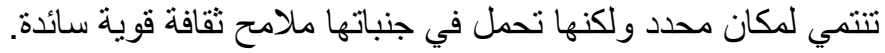

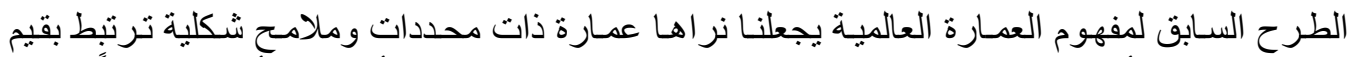

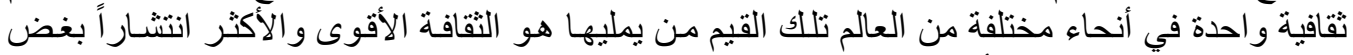
النظر عن الملامح المكانية أو الإنسانية.

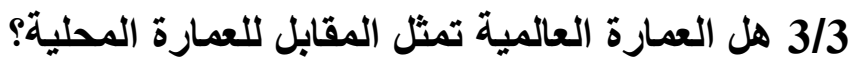

هل العمارة المحلية تمثل المقابل للعمارة العالمية؟... و هل يجب علينا الاختيار بين المحلية و العالميـة؟...

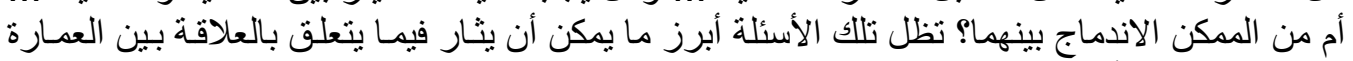
المحلية و العالمبة أو العولمية المية.

" يرى البعض أن الاستجابة لظروف المكان الطبيعية والمناخية تظل غير كافية بمفردهـا لوسم العمارة

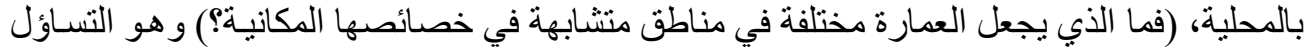
الذي طرحه "Rapoport" يتساءل في كتابه (House Form and Culture) 
فالعمـارة المحلية منطقها أنها لا يوجد مبرر للنتـابه بين المنتج المعمـاري في البلاد المتتوعـة فالإطـار العـام

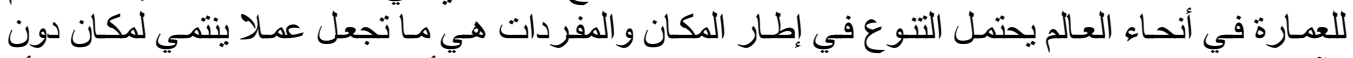

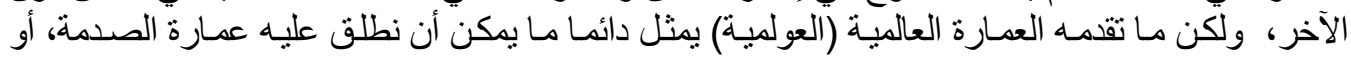

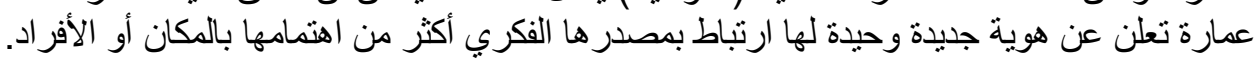

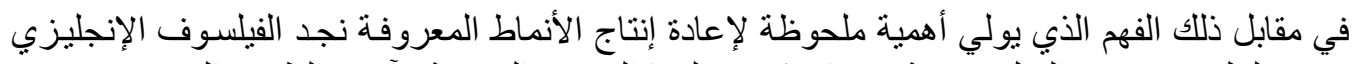

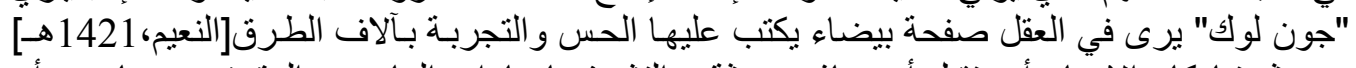

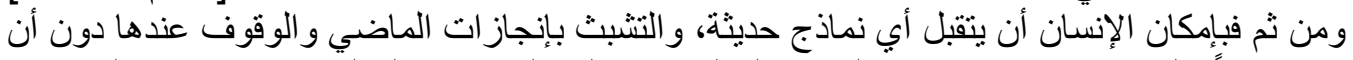

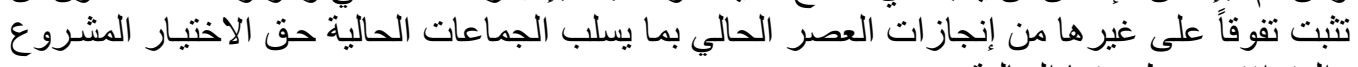
و المتو افق مع ظروفها الحالية. رغم ما يبدو من تباين واضح بين المحلية والعالمية، إلا أن إدخال التأثير العولمي هو في في حقيقته عدم

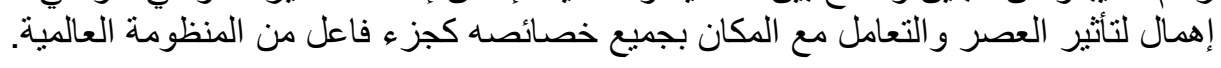

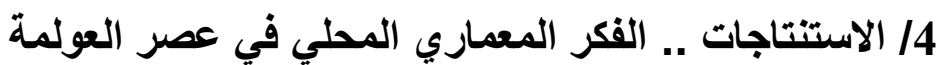

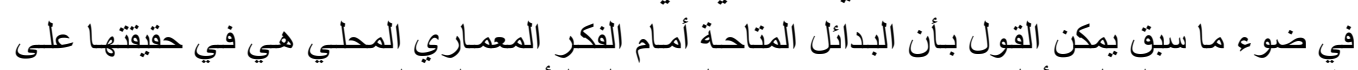

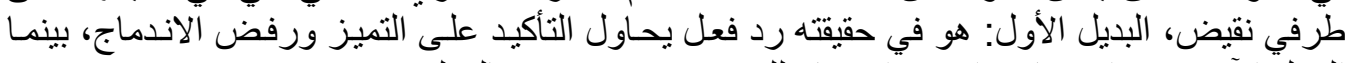

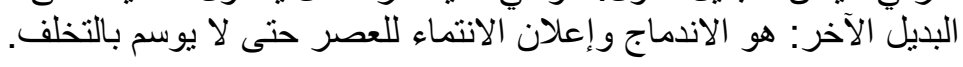

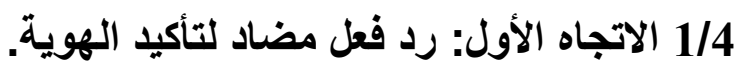

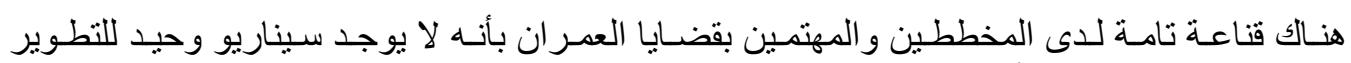

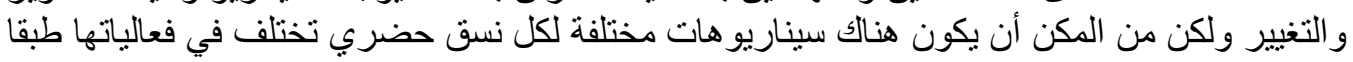

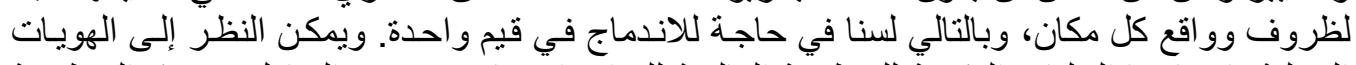

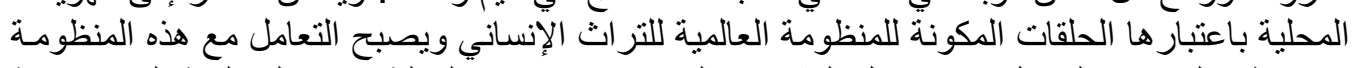

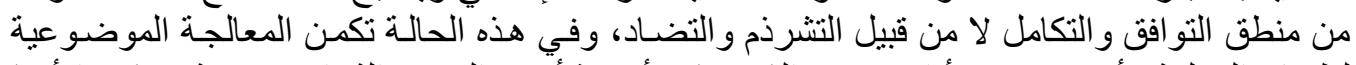

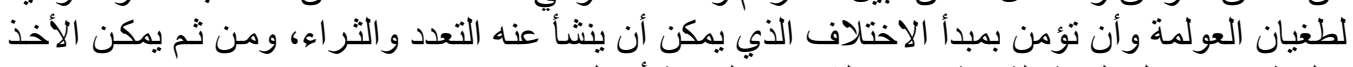

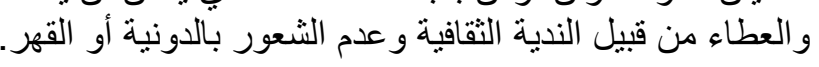

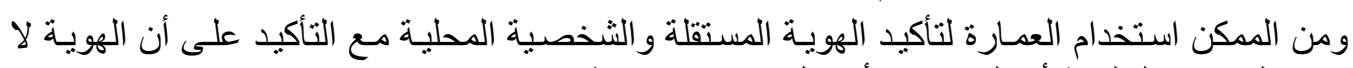

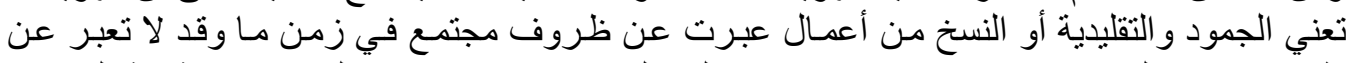

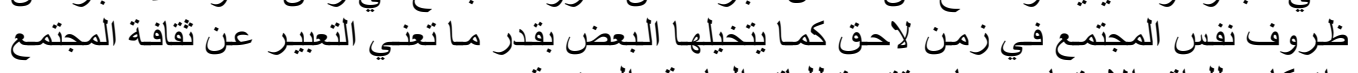
و انعكاس للو اقع الاجتماعي بما يحقق منطلباته المادية و المعنوية.

\section{2/4 الاتجاه الثاني: حركة مع تيار العولمة}

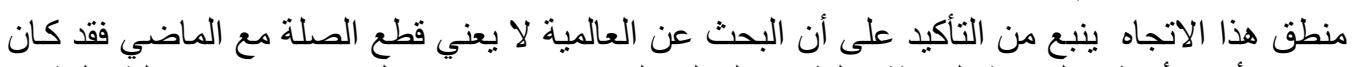

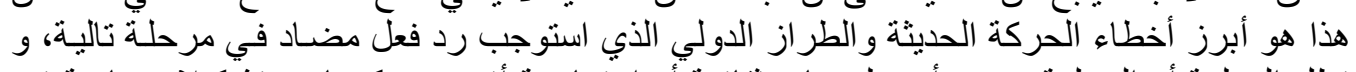

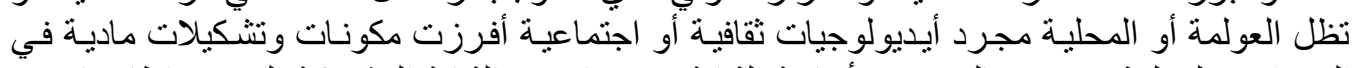

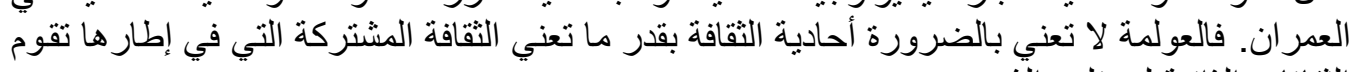

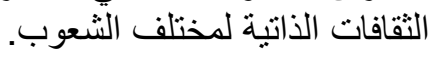

لكن الخروج من المنطلقات النظرية إلى التطبيقات العملية لهذا الاتجاه نجده يتفرع إلى اتجاهين:

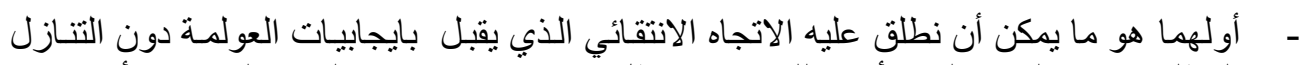

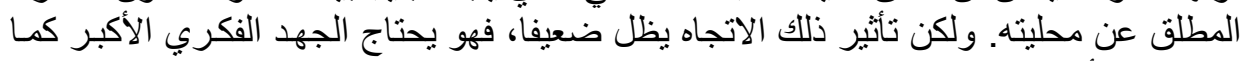

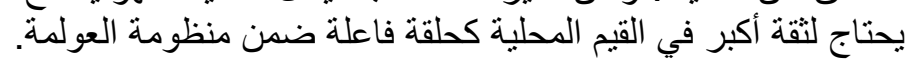




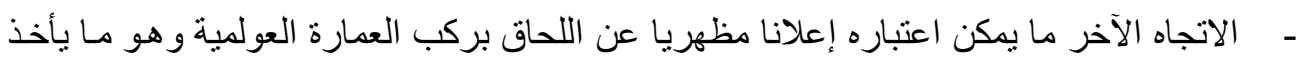

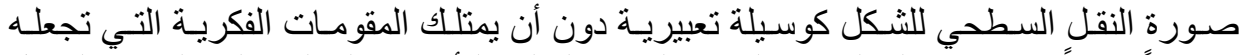

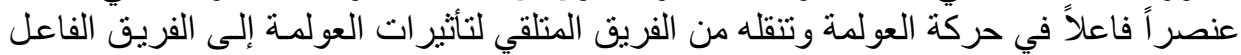

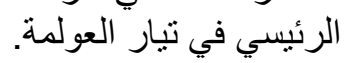

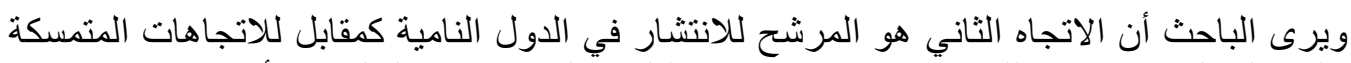

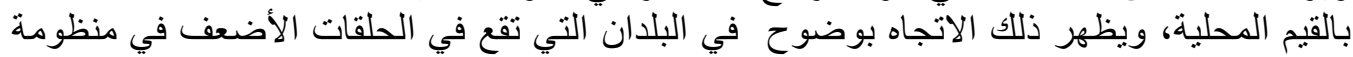

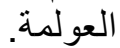

\section{5/ الخلاصة.}

- - تمثل العولمة مرحلة أساسية في تاريخ البشرية لا يمكن إهمال تأثير ها.

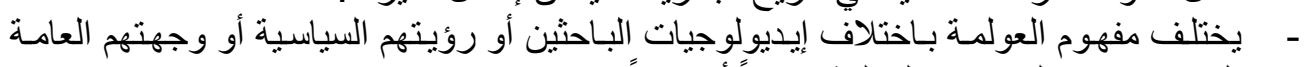

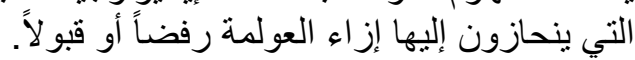

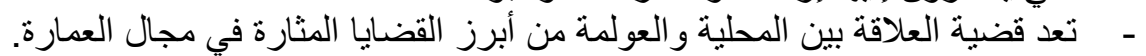

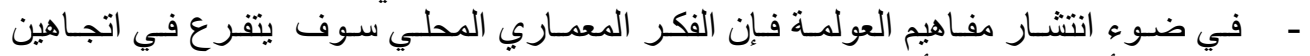

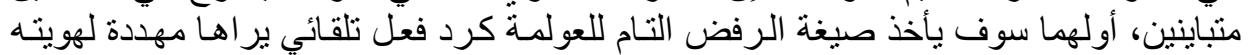

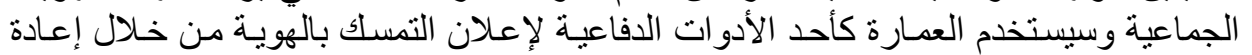

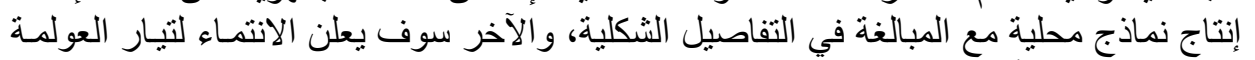

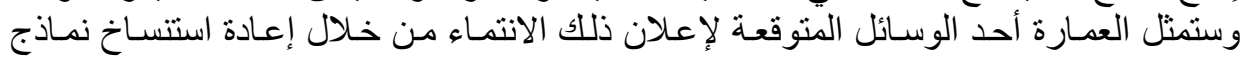

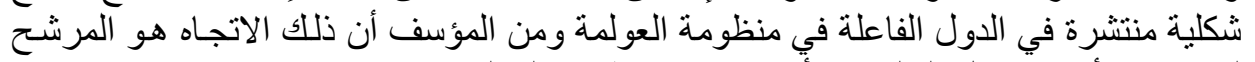

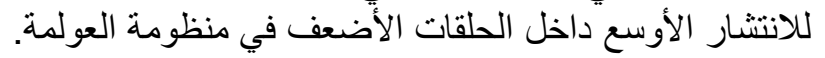




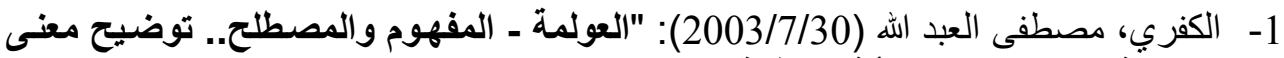

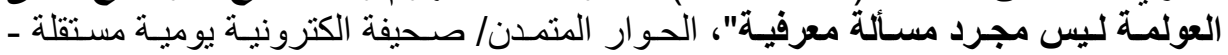

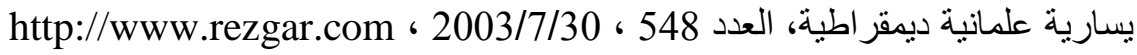

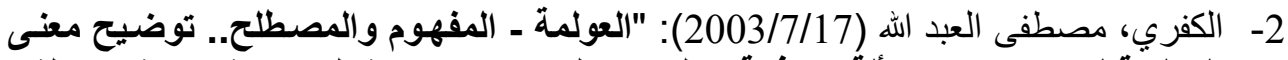

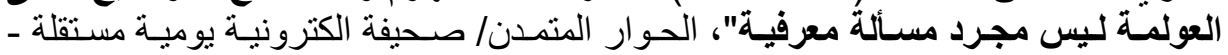

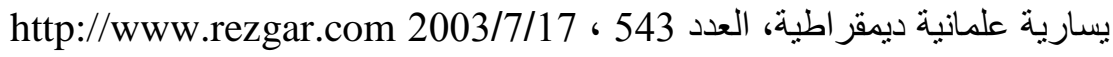

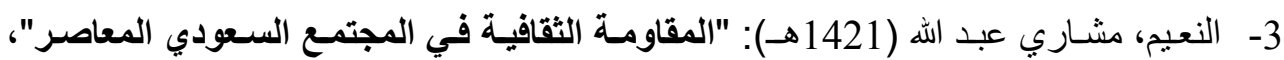

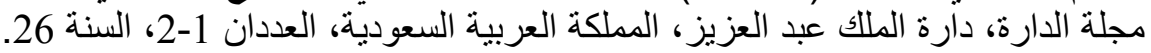

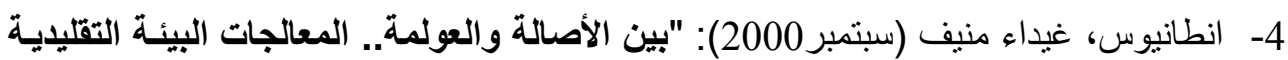

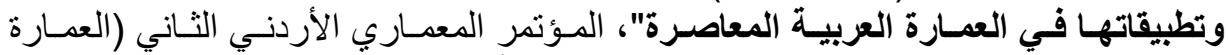

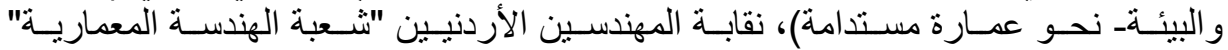

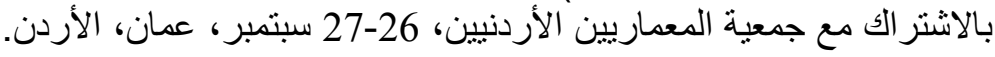

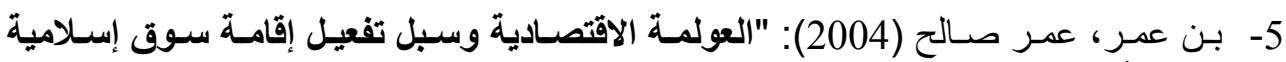

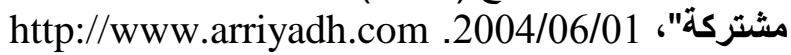

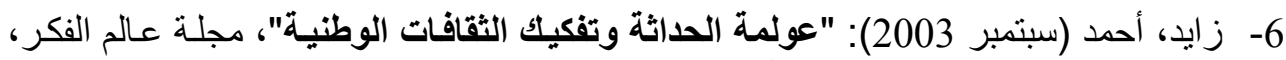

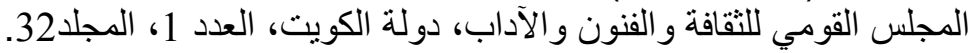

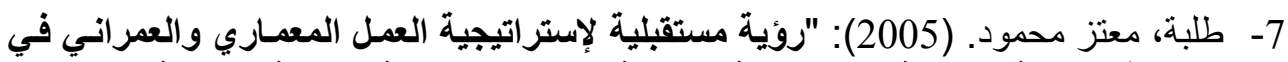

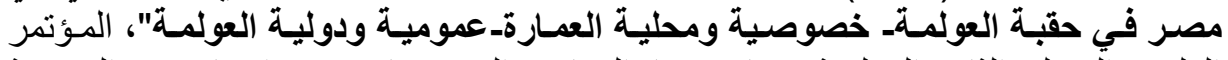

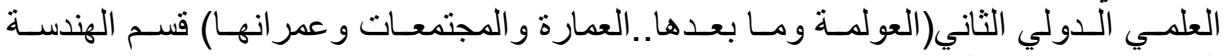

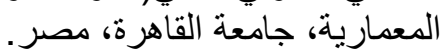

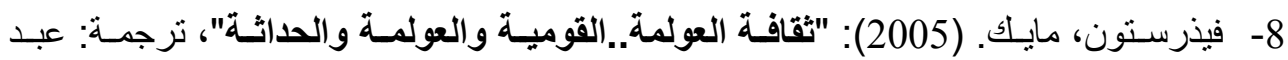

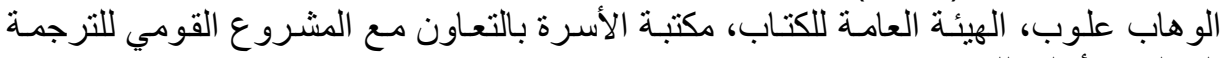

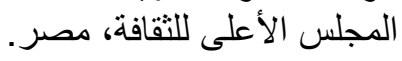

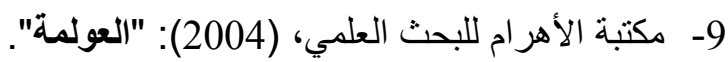

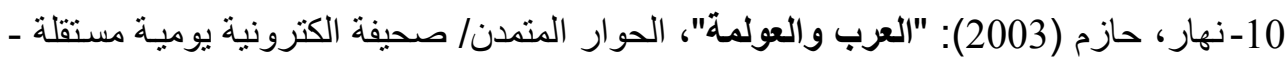

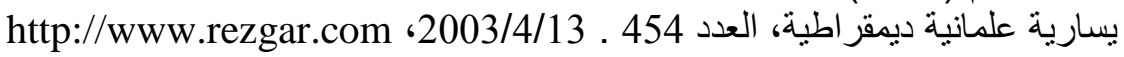

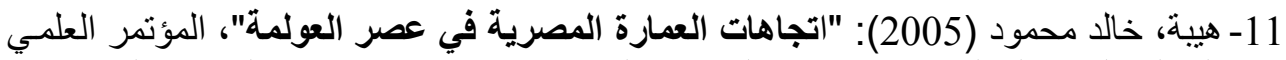

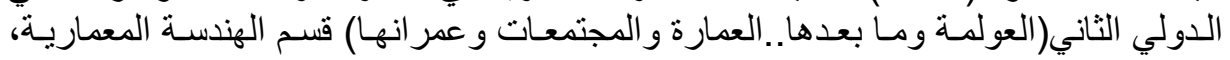
جامعة القاهرة، مصر.

12------ (2004) : "(قتصاد المعرفة أحد صور العولمة"، مجلة العربي، الكويت، العدد 551.

13- Chemrouk, Naima Chabbi. (2000): "Globalizing and Cultural Identity", TRIALOG, A Journal for Planning and Building in the Third World, No 64-1.

14- Colquhoun, Alan. (1991): "Essays in Architectural Criticism, Modern Architecture and Historical Change", 6th Printing, MIT Press, London, England.

15- Eisnman, Peter. (1988): "Architecture as a Second Language: The Text of Between. In Diani", Marco \& Ingraham, Catherine (Ed.), (Restructuring Architectural Theory), Northwestern University Press, Illinois, USA. 
16- Hillier, Bill. (1993): "Specifically architectural theory", The Harvard Architecture Review, V.9

17-Rapoport, Amos. (1969): "House Form and Culture", Prentice-Hall, Inc, London, England. 